\section{Psychological Medicine}

cambridge.org/psm

\section{Original Article}

Cite this article: Yu R, Branje S, Meeus W, Cowen P, Fazel S (2019). Depression, violence and cortisol awakening response: a 3-year longitudinal study in adolescents. Psychological Medicine 49, 997-1004. https:// doi.org/10.1017/S0033291718001654

Received: 5 October 2017

Revised: 5 April 2018

Accepted: 29 May 2018

First published online: 17 July 2018

Keywords:

Adolescence; aggression; cortisol awakening response; depression; violence

Author for correspondence:

Seena Fazel, E-mail: seena.fazel@psych.ox.ac. uk

\title{
Depression, violence and cortisol awakening response: a 3-year longitudinal study in adolescents
}

\section{Rongqin $\mathrm{Yu}^{1}$, Susan Branje ${ }^{2}$, Wim Meeus ${ }^{2,3}$, Philip Cowen ${ }^{1}$ and Seena Fazel ${ }^{1}$}

${ }^{1}$ Department of Psychiatry, University of Oxford, Oxford, UK; ${ }^{2}$ Department of Youth and Family, Utrecht University, Utrecht, The Netherlands and ${ }^{3}$ Department of Developmental Psychology, Tilburg University, Tilburg, The Netherlands

\begin{abstract}
Background. Despite evidence of links between depression and violent outcomes, potential moderators of this association remain unknown. The current study tested whether a biological marker, cortisol, moderated this association in a longitudinal sample of adolescents.

Methods. Participants were 358 Dutch adolescents (205 boys) with a mean age of 15 years at the first measurement. Depressive symptoms, the cortisol awakening response (CAR) and violent outcomes were measured annually across 3 years. The CAR was assessed by two measures: waking cortisol activity (CAR area under the curve ground) and waking cortisol reactivity (CAR area under the curve increase). Within-individual regression models were adopted to test the interaction effects between depressive symptoms and CAR on violent outcomes, which accounted for all time-invariant factors such as genetic factors and early environments. We additionally adjusted for time-varying factors including alcohol drinking, substance use and stressful life events.

Results. In this community sample, $24 \%$ of adolescents perpetrated violent behaviours over 3 years. We found that CAR moderated the effects of depressive symptoms on adolescent violent outcomes ( $\beta$ s ranged from -0.12 to -0.28 ). In particular, when the CAR was low, depressive symptoms were positively associated with violent outcomes in within-individual models, whereas the associations were reversed when the CAR was high.

Conclusions. Our findings suggest that the CAR should be investigated further as a potential biological marker for violence in adolescents with high levels of depressive symptoms.
\end{abstract}

\section{Introduction}

Adolescent depression has been linked to a wide range of negative outcomes including suicide (Hawton et al., 2012), substance use (Henry et al., 1993) and various social impairments (Rudolph, 2009). Increasing evidence suggests that depression is also associated with an elevated risk of violent outcomes. The increased risk of violence has been reported in several longitudinal studies (Capaldi and Stoolmiller, 1999; Kofler et al., 2011; Fazel et al., 2015; Yu et al., 2017) including using sibling and twin designs (Fazel et al., 2015). In addition, other designs, including cross-sectional and prevalence studies in selected samples, are consistent with this link (Arseneault et al., 2000; Coid et al., 2006; Fairchild et al., 2008; Ferguson et al., 2009; Piko and Pinczés, 2014). However, inconsistent findings have been reported, as several studies found no clear associations between depression and violent outcomes (Chen et al., 2012; van Dorn et al., 2012; Marsh et al., 2016). Clarifying moderators of the links between depression and violent outcomes is needed and may assist in the design of effective prevention and intervention programmes.

One potentially important moderator of the link between depression and violent outcomes could be differences in stress sensitivity (Raine, 2002; Hellhammer et al., 2009). Blunted hypothalamic-pituitary-adrenal (HPA) activity is a component of stress hypoarousal that may reduce the ability to share the distress of others (von Polier et al., 2013; Johnson et al., 2014). Cortisol is the primary hormonal end product of the HPA axis and its response or activity is an important biological indicator of self-regulation, playing a central role in the regulation of emotional and behavioural responses to environmental stressors. Low cortisol activity is an indication of blunted HPA activity and is hypothesized to be linked to antisocial behaviours (Raine, 2002). The cortisol awakening response (CAR) refers to the marked morning rhythm normally exhibited by cortisol within the first hour after awakening, and is characterized by a rapid increase in levels upon awakening, peaking at around $30 \mathrm{~min}$ post-awakening, and declining thereafter (Wüst et al., 2000). The overall volume of cortisol released over the waking period [area under the curve ground (AUCg)] and the absolute changes in cortisol levels postawakening [area under the curve increase (AUCi)] provide useful and reliable markers of HPA activity (Pruessner et al., 1997). 
Support for the association between CAR and antisocial behaviours comes from studies that report lower morning cortisol levels and increased risk of violent outcomes in clinical samples with attention-deficit hyperactivity and conduct disorders (Pajer et al., 2001; Freitag et al., 2009) and general community samples (Shirtcliff et al., 2005; Platje et al., 2013). In particular, several longitudinal studies have reported that low morning cortisol levels predicted adolescent aggressive behaviours 5 years later (Shoal et al., 2003) and persistent aggressive behaviours over 3 years (Platje et al., 2013). However, this is not a consistent finding. For instance, studies in predominantly male samples of adolescent offenders and disruptive youth have shown non-significant links (Dabbs et al., 1991; Scerbo and Kolko, 1994).

Previous studies have shown that psychological factors such as depression and biological features such as CAR can independently lead to aggressive and violent behaviours. From a psychobiological point of view, aggressive and violent behaviours can also be regarded as the outcome of the interaction between psychological and biological factors (Quay, 1993). Thus, depression is likely to interact with CAR in predicting adolescent violent outcomes. Based on prior research (Platje et al., 2013; Fazel et al., 2015), we propose the following hypotheses on the patterns of interaction. Specifically, when adolescents have higher levels of depressive symptoms, they have an increased risk of violent outcomes, in particular when their CAR decreases. The theoretical basis for this is that as depressive symptoms include pervasive low mood, negativity, irritability, agitation and pessimism, when these symptoms are experienced in combination with low CAR, adolescents will have more difficulty dealing with or regulating these symptoms and be more likely to act out their distress with violence and aggression towards others. In contrast, high CAR may act as a protective factor in the link between depressive symptoms and violence. In particular, it might serve as a biological buffer to prevent individuals from acting out depressive symptoms with violent behaviours. Thus, we hypothesize that depression is not associated with violent outcomes when CAR is higher. We tested these hypotheses with the data from a longitudinal study of adolescents. Understanding the interplay between cortisol response and depressive symptoms is important as it could contribute to the possibility of using biomarkers as part of prognostic assessments in mental health (Vitacco et al., 2015).

\section{Methods}

\section{Sample}

Participants were 358 adolescents (205 boys) who took part in cortisol awaking measurements at wave 3 of the ongoing longitudinal RADAR Young study $(N=497$, Research on Adolescent Development And Relationships). RADAR Young is a cohort study focusing on adolescent developmental outcomes including internalizing and externalizing problem behaviours and physiological developments. The current study was based on the data from the third to fifth annual waves. The mean age of the participants in wave 3 was 15.0 years (ranging from 14.0 to 17.6; S.D. = 0.5). All participants identified themselves as Dutch. In this sample, $10.5 \%$ were from low socioeconomic status family, which was defined as having a father and mother who were unemployed or held a manual job (Statistics Netherlands, 1993). In addition, analyses of all variables used in this study revealed a normed $\chi^{2}\left(\chi^{2} /\right.$ df) of 1.04, which indicates that the pattern of the missing data was not materially different from a missing completely at random pattern (Bollen, 1989).

\section{Procedure}

Participants were recruited from various Dutch elementary schools. Across 3 years at a similar time of each year, adolescents filled out questionnaires on socio-demographic, depression and violence measures during annual home visits, supervised by trained research assistants. In addition to the administration of the behavioural measurements, research assistants gave detailed verbal and written instructions for cortisol measurements. The RADAR study has been approved by the medical ethics committee of the University Medical Center in Utrecht, The Netherlands.

\section{Measurements}

\section{Depressive symptoms}

The Reynolds Adolescent Depression Scale, second edition (RADS-2) (Reynolds, 2002) was used to measure depression symptoms. This self-report questionnaire includes 23 items (e.g. 'I feel nobody cares about me.') Adolescents responded to the questionnaire on a four-point Likert scale, ranging from 1 (almost never) to 4 (usually). Scores can range from 23 to 92. Previous research has shown good psychometric properties of RADS-2 (e.g. test-retest reliabilities $>0.7$ in diverse samples) (Reynolds, 2004). In the current sample, the Cronbach's $\alpha$ of this scale was 0.9 in all three annual waves and the average test-retest reliability with a 1-year interval was 0.7 across waves.

\section{Violent behaviours}

Adolescents' violent behaviours in the last 12 months were measured on a self-reported scale based on a large international comparative study on delinquency (Enzmann et al., 2010). Violent behaviours were measured with five items including: stealing from person with threat/force, assaulting, injuring someone with a weapon, and beating and/or kicking (with/without) causing injury. Adolescents responded on a five-point scale, ranging from 0 (never) to 4 (more than ten times). Scores can range from 0 to 20. The Cronbach's $\alpha$ s of this scale were 0.5 at wave $3,0.7$ at wave 4 and 0.6 at wave 5 and the average test-retest reliability with a 1-year interval was 0.5 across 3 years.

\section{Physical aggression}

Physical aggression was measured with a self-reported questionnaire (Linder et al., 2002) via six items (e.g. 'I push or punch others to get what I want.') Adolescents responded to these items on a seven-point Likert scale, ranging from 1 (not at all true) to 7 (very true). Scores can range from 6 to 42. Prior research has indicated good reliability and validity (Linder et al., 2002). The Cronbach's $\alpha$ for the scale was 0.9 in all three waves and the average test-retest reliability with a 1 -year interval was 0.7 across the three waves.

\section{Cortisol awakening responses}

$\mathrm{CAR}_{\mathrm{AUCg}}$ and $\mathrm{CAR}_{\mathrm{AUCi}}$ were measured in the saliva that was collected by passive drooling, immediately after awakening (Cort0), $30 \mathrm{~min}$ (Cort30) and $60 \mathrm{~min}$ (Cort60) later. Cortisol sampling took place in February and March of each consecutive year, as soon as possible after assessing depression and violent outcomes from wave 3 to 5 . The saliva sampling was scheduled on a typical weekday during the school year. Participants were instructed to 
rinse their mouths with water before sampling, and not to eat, drink, smoke or brush their teeth before completing Cort60. They were requested to collect their saliva through a small straw into a polypropylene tube, and label these tubes with the time and date of sampling. After collection, participants were asked to store the samples in the refrigerator and send them by mail to the research centre the same day. At the research centre, the cortisol collections were stored uncentrifuged at $-20{ }^{\circ} \mathrm{C}$ until analysis. Salivary cortisol levels were analysed using electrochemiluminescence immunoassay (E170 Roche, Switzerland). The lower detection limit was $0.5 \mathrm{nmol} / \mathrm{l}$, and the mean intra-assay and inter-assay coefficients of variation were $3 \%$ and $12 \%$, respectively. Cases were excluded from analyses if the cortisol data used incorrect sampling time, or if it was unclear how it was sampled (i.e. not registered) or contaminated (e.g. by smoking or brushing teeth). In the current study, 358 participants provided qualified data. $\mathrm{CAR}_{\mathrm{AUCg}}$ is a summary parameter of the repeated measurements of CAR. Thus, it is an estimation of total adrenal cortisol secretion during the first hour after awakening. $\mathrm{CAR}_{\mathrm{AUCi}}$ is the absolute change in cortisol levels during the first hour post-awakening. We calculated the $\mathrm{CAR}_{\mathrm{AUCg}}$ and $\mathrm{CAR}_{\mathrm{AUCi}}$ with the formula provided by Pruessner et al. (Pruessner et al. 2003). Specifically, $\mathrm{CAR}_{\mathrm{AUCg}}=($ Cort $30+$ Cort 0$) / 2+(\operatorname{Cort} 60+\operatorname{Cort} 30) / 2$ and $\mathrm{CAR}_{\mathrm{AUCi}}=(\operatorname{Cort} 30+\operatorname{Cort} 0) /$ $2+(\operatorname{Cort} 60+\operatorname{Cort} 30) / 2-(3-1) \times$ Cort 0 .

\section{Time dynamic covariates}

As alcohol drinking, substance use and stressful life experiences might affect both CAR (Clow et al., 2004; Platje et al., 2013) and violent outcomes (Hoffmann and Cerbone, 1999), the effects of these factors were adjusted. Alcohol use over the last 4 weeks was assessed with a question with six response options, ranging from 'none' to 'daily'. Substance use was defined as illicit drug use that was assessed with six questions (e.g. How many times have you used XTC/marijuana/cocaine/mushrooms/amphetamine/heroin in the last 12 months?). Responses range from '0 time' to ' 40 times or more'. Stressful experiences included sexual assault, physical assault and being threatened with violence, and were measured with the International Crime Victims Survey (Nieuwbeerta, 2002). Participants were asked to indicate their stressful life experiences with five items (e.g. Has anyone ever touched you against your will in any sexual way in the past year?). Responses include 'yes' and 'no'. These time-varying factors were measured at the same three annual waves as the other predictors.

\section{Statistical analyses}

We adopted a within-individual design applying fixed-effects methods to examine the interaction effects between depressive symptoms and CAR on adolescent violent outcomes. Unlike between-individual approaches, estimators in the within-individual model rely only on within-individual changes over time. Adolescence offers a promising period for using this design as individuals pass through significant changes in all the key studied variables (Moffitt, 1993; Shirtcliff et al., 2012; Thapar et al., 2012; Platje et al., 2013).

In addition, in the within-individual model, each individual acts as their own control. As no changes over time occur in timeinvariant variables, the effects of them are automatically controlled for in the within-individual design (Gunasekara et al., 2013). Further details of the rationale and regression equations of this method are reported elsewhere (Allison, 2009). As many time-invariant confounding factors, such as genetic and early environmental factors (Risch et al., 2009; Roisman et al., 2009; Byrd and Manuck, 2014; St Clair et al., 2015), might be linked to the studied variables, this method provides parameter estimates that are less subject to bias (Allison, 2009; Gunasekara et al., 2013).

We further extended our model to adjust for time-varying factors including alcohol drinking, hard drug use and stressful life events at each of the three measurement points. In addition, as gender differences have been suggested in the developmental changes of and interactions among studied variables (Dodge et al., 2006; Card et al., 2008; Avenevoli et al., 2015), as well as in other unmeasured time-varying variables such as sex hormones including testosterone and oestradiol (Popma et al., 2007; Mehta et al., 2015; Tackett et al., 2015), we conducted within-individual analyses for boys and girls separately. We also tested three-way interactions between depression, CAR and gender to assess whether the gender differences were statistically significant. Furthermore, we examined whether the interaction effects between depression and CAR differed by age. In addition, as within-individual correlations between $\mathrm{CAR}_{\mathrm{AUCi}}$ and $\mathrm{CAR}_{\mathrm{AUCg}}$ were small to moderate ( $r$ was 0.42 in girls and 0.16 in boys; Table 1 ), we included $C_{A A R}$ and $C_{A A R}$ AUCi the same model. Data were analysed using STATA SE version 14 (StataCorp, 2015).

When the interaction effects between depression and CAR were significant, we examined the shape of the interaction by probing the interaction effects. To examine this, simple slopes for each interaction were presented [at 1 standard deviation (s.D.) above and below mean of the moderators $\left(\mathrm{CAR}_{\mathrm{AUCg}}\right.$ and $\left.\mathrm{CAR}_{\mathrm{AUCi}}\right)$ ]. Moreover, we applied the Johnson-Neyman technique, using the computational tool of Preacher et al. (Preacher et al., 2006) to calculate the values of moderators $\left(\mathrm{CAR}_{\mathrm{AUCg}}\right.$ and $\mathrm{CAR}_{\mathrm{AUCi}}$ ) at which the regression of outcomes (violence and aggression) on predictors (depressive symptoms) moves from non-significance to significance (http://www.quantpsy.org/ interact/mlr2.htm) (Hayes and Matthes, 2009).

\section{Results}

\section{Descriptive statistics}

Table 1 shows an overview of means of and bivariate intercorrelations among depressive symptoms, CAR and violent outcomes for adolescents across three waves. This descriptive information and correlations were based on observations (including repeated measurements of individuals) across three time points. In this community sample, $24 \%$ of adolescents perpetrated violent behaviours over 3 years. There were positive correlations between depression and violent outcomes. In general, there was no association between CAR and depression, expect for a small correlation between depression and $\mathrm{CAR}_{\mathrm{AUCg}}$ in boys $(r=0.10)$ and no association between CAR and violent outcomes, expect for small correlations between $\mathrm{CAR}_{\mathrm{AUCg}}$ and aggression in girls $(r=0.11)$ and $\mathrm{CAR}_{\mathrm{AUCi}}$ and violence in boys $(r=0.09)$. Table 2 and Table 3 present the results of our final models examining the interaction effects between CAR and depressive symptoms on adolescent violent outcomes.

\section{Interaction effects between CAR and depressive symptoms on adolescent violent outcomes}

Three of the four models showed significant interaction effects between CAR and depressive symptoms in predicting adolescent 


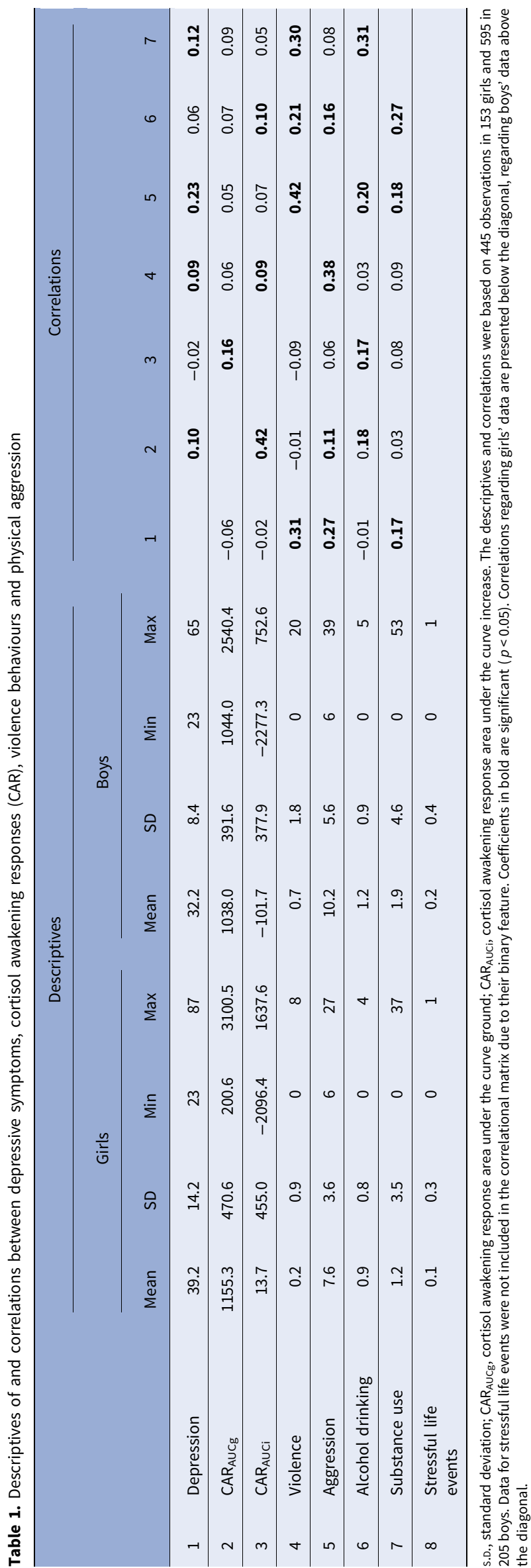

violent outcomes at the within-individual level over 3 years, showing that increases in depressive symptoms were associated with elevated risk of violent outcomes when CAR was low. The interaction effects between $\mathrm{CAR}_{\mathrm{AUCi}}$ and depressive symptoms on violent outcomes including both violence and aggression were significant in girls but not in boys (Table 2). The interaction effect in predicting violence was marginally stronger in girls than boys [B (s.E.) $=-0.20(0.11), \beta=-0.13, p=0.07]$. In addition, there was a significant interaction effect between $\mathrm{CAR}_{\mathrm{AUCg}}$ and depressive symptoms in predicting aggression in boys, whereas no such interaction was present in girls (Table 3). Three-way interaction analyses indicated that this effect was significantly stronger in boys than girls [B (s.E.) $=1.02(0.36), \beta=0.20, p<0.01$ ]

These interaction effects indicated that the associations between depressive symptoms and adolescent violent outcomes differed for varying levels of $\mathrm{CAR}_{\mathrm{AUCi}}$ in girls and $\mathrm{CAR}_{\mathrm{AUCg}}$ in boys. Region of significance tests revealed that when $\mathrm{CAR}_{\mathrm{AUCi}}$ levels were $\leqslant-1.09$ s.D. (standard deviation) and $\leqslant-1.71$ S.D. below the mean, higher depressive symptoms significantly predicted higher levels of violence and aggression in girls, respectively. The reverse was true for the associations between depression and the two violent outcomes when $C_{A A R_{A C i}}$ was higher than certain levels. Specifically, when $\mathrm{CAR}_{\mathrm{AUCi}}$ levels were $\geqslant 0.65$ S.D. and $\geqslant 0.85$ S.D. above the mean, higher depressive symptoms significantly predicted lower levels of girls' violence and aggression, respectively. In addition, $\mathrm{CAR}_{\mathrm{AUCg}}$ moderated the association between depressive symptoms and aggressive behaviours in boys. When the $\mathrm{CAR}_{\mathrm{AUCg}}$ level was $\leqslant-0.24$ s.D. below the mean, depressive symptoms were positively related to aggressive behaviours in boys, whereas when the $C_{A A R}$ level was $\geqslant 3.04$ s.D. above the mean, depressive symptoms were negatively associated with aggressive behaviours. The interactive effects were visualized by showing simple slopes for high in CAR (at 1 S.D. above the mean) and low in CAR (at 1 S.D. below the mean) (Fig. 1 $a-c$ ). The simple slopes for girls with high and low $\mathrm{CAR}_{\mathrm{AUCi}}$ are depicted in Fig. $1 a$ and $b$. The simple slopes for boys with high and low $\mathrm{CAR}_{\mathrm{AUCg}}$ are depicted in Fig. $1 c$.

We found that the interaction effect between depression and $\mathrm{CAR}_{\mathrm{AUCg}}$ in predicting aggression in boys varied by age. The three-way interaction effect between depression, $\mathrm{CAR}_{\mathrm{AUCg}}$ and age was: $\mathrm{B}$ (s.E.) $=-0.59(0.26), \beta=-0.10, p=0.03$, which suggested a stronger interaction effect when boys were older. No other age effects were found in the interaction effects.

In addition, we did sensitivity analyses to test whether the interaction effects between depression and CAR existed for subtypes of aggressive behaviours. We found that the depression $\times \mathrm{CAR}_{\mathrm{AUCg}}$ interaction effects occurred in predicting both proactive $[\mathrm{B}($ s.E. $)=$ -0.38 (0.12), $\beta=-0.15, p<0.01]$ and reactive physical aggression [B (s.E.) $=-0.26(0.14), \beta=-0.07, p=0.06$ ] in boys. Further, there were depression $\times \mathrm{CAR}_{\mathrm{AUCi}}$ interaction effects on both proactive [B (s.E.) $=-0.33(0.10), \beta=-0.20, p<0.01]$ and reactive physical aggression [B (s.E.) $=-0.23(0.12), \beta=-0.10, p=0.06$ ] in girls.

\section{Discussion}

In this study of 358 adolescents who were assessed annually for 3 years, we examined interactions between depressive symptoms and CAR in predicting adolescent violent outcomes using within-individual models. These models, where the effects are estimated based on variations within the same person, allowed for time-invariant factors to be accounted for, such as genetic background and early environmental experiences. We found 
Table 2. Interaction effects between depressive symptoms and cortisol awakening response (CAR) on adolescent violence

\begin{tabular}{|c|c|c|c|c|}
\hline \multirow{2}{*}{$N=358$} & \multicolumn{4}{|c|}{ Violence } \\
\hline & \multicolumn{2}{|c|}{ Girls $(n=153)$} & \multicolumn{2}{|c|}{ Boys $(n=205)$} \\
\hline Depression & $-0.03(0.10)$ & -0.03 & $0.03(0.10)$ & 0.02 \\
\hline $\mathrm{CAR}_{\mathrm{AUCg}}$ & $-0.01(0.06)$ & -0.02 & $-0.01(0.08)$ & -0.01 \\
\hline Depression $\times \mathrm{CAR}_{\mathrm{AUCg}}$ & $-0.00(0.06)$ & 0.00 & $-0.08(0.07)$ & -0.04 \\
\hline Depression $\times \mathrm{CAR}_{\mathrm{AUCi}}$ & $-0.26(0.06)$ & $-0.28^{\star \star \star}$ & $0.00(0.07)$ & 0.00 \\
\hline Alcohol drinking & $0.11(0.06)$ & 0.11 & $0.09(0.08)$ & 0.05 \\
\hline Substance use & $0.03(0.09)$ & 0.03 & $-0.08(0.12)$ & -0.04 \\
\hline
\end{tabular}

$\mathrm{CAR}_{\mathrm{AUCg}}$, cortisol awakening response area under the curve ground; $\mathrm{CAR}_{\mathrm{AUCl}}$, cortisol awakening response area under the curve increase.

${ }^{\star \star \star} p<0.001 ;{ }^{\star \star} p<0.01 ;{ }^{\star} p<0.05$.

Table 3. Interaction effects between depressive symptoms and cortisol awakening response (CAR) on adolescent physical aggression

\begin{tabular}{|c|c|c|c|c|}
\hline \multirow{2}{*}{$N=358$} & \multicolumn{4}{|c|}{ Physical aggression } \\
\hline & \multicolumn{2}{|c|}{ Girls $(n=153)$} & \multicolumn{2}{|c|}{ Boys $(n=205)$} \\
\hline Depression & $-0.10(0.28)$ & -0.03 & $0.55(0.34)$ & 0.10 \\
\hline $\mathrm{CAR}_{\mathrm{AUCg}}$ & $-0.05(0.16)$ & -0.01 & $-0.02(0.27)$ & 0.00 \\
\hline Depression $\times \mathrm{CAR}_{\mathrm{AuCg}}$ & $0.06(0.16)$ & 0.02 & $-0.65(0.24)$ & $-0.12^{\star \star}$ \\
\hline Depression $\times \mathrm{CAR}_{\mathrm{AUCi}}$ & $-0.57(0.17)$ & $-0.16^{\star \star}$ & $-0.03(0.22)$ & -0.01 \\
\hline Alcohol drinking & $0.29(0.18)$ & 0.08 & $0.25(0.27)$ & 0.04 \\
\hline Substance use & $0.72(0.25)$ & $0.20^{\star \star}$ & $0.09(0.40)$ & 0.02 \\
\hline
\end{tabular}

$\mathrm{CAR}_{\mathrm{AUCg}}$, cortisol awakening response area under the curve ground; $\mathrm{CAR}_{\mathrm{AUC}}$, cortisol awakening response area under the curve increase. ${ }^{\star \star} p<0.01 ;{ }^{\star} p<0.05$.

that CAR moderated the links between depressive symptoms and adolescent violent outcomes. When $\mathrm{CAR}_{\mathrm{AUCi}}$ were low, increases in depressive symptoms were positively associated with increases in violent and aggressive behaviours at the within-individual level in girls. A similar interaction pattern appeared between depressive symptoms and $\mathrm{CAR}_{\mathrm{AUCg}}$ in predicting aggressive behaviours at the within-individual level in boys.

One explanation for the moderating effect of CAR is that cortisol could be associated with psychological variables, such as callous and unemotional traits, which are on the pathway between depression and violent outcomes. Low cortisol has been reported in individuals with psychopathic and callous-unemotional traits (von Polier et al., 2013; Johnson et al., 2014). Hence, it is possible that low cortisol may lead to disinhibition (Freitag et al., 2009) and possibly more expression of callous-unemotional traits (von Polier et al., 2013; Johnson et al., 2014) which in turn may be linked to higher risk of violent outcomes in depressed individuals. However, this potential pathway will need to be validated. Furthermore, low CAR has been linked to conduct disorders (Pajer et al., 2001), which are associated with various violent behaviours (Arseneault et al., 2000). Thus, conduct disorders could potentially function as a mediator through which the risk of violent outcomes increases when an individual's depressive symptoms increased and CAR decreased. Finally, blunted CAR has been associated with poor behavioural regulation when confronting environmental stressors (Raine, 2002). Dysfunctional regulation might also lead individuals to act out violently when depressive symptoms are higher and CAR is lower. More research is required to unpack different potential mechanisms behind the interaction effects.

Our study showed differential patterns of interaction effects between CAR and depression among boys and girls. The moderating role of $\mathrm{CAR}_{\mathrm{AUCi}}$ in the effects of depressive symptoms on violence and aggression was significant only in girls, whereas the moderating effects of $\mathrm{CAR}_{\mathrm{AUCg}}$ appeared in predicting aggression in boys. One possibility could be that other sex hormones, such as testosterone, play a role in the interaction between depression and CAR. The participants in this study were followed from ages 15 to 17, which is an important period of sex hormonal development in adolescence with oestrogen and progesterone 

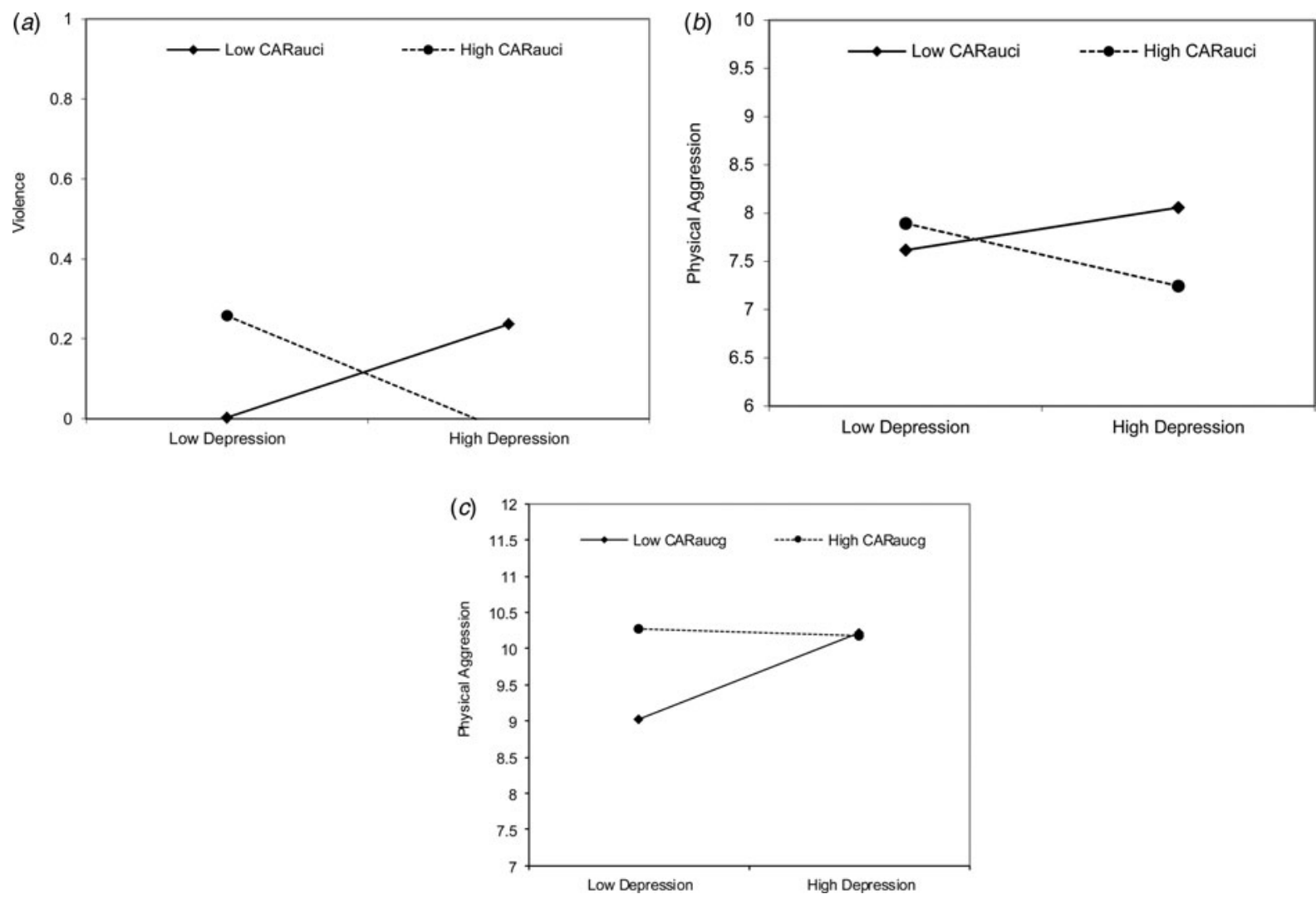

Fig. 1. (a) Interaction effects between depression and $C A R_{A U C i}$ in predicting violence in girls. $(b)$ Interaction effects between depression and $C A R_{A U C i}$ in predicting aggression in girls. (c) Interaction effects between depression and $C_{A R} R_{A \cup C}$ in predicting aggression in boys. $(a-c) C_{A R C}$, cortisol awakening response area under the curve increase; $C_{A R}$, cortisol awakening response area under the curve ground. Low, one s.D. below mean; High, one S.D. above mean.

increasing in girls and testosterone rising in boys (Rowe et al., 2004). Prior studies have showed that low cortisol predicts high levels of physical aggression particularly when the levels of testosterone are high (Popma et al., 2007). It is possible that sex hormones interact with CAR and lead to differential interaction patterns between depression and CAR. For instance, it could be that depressive symptoms increase the risk of violent outcomes, but only when cortisol is low and testosterone is high. Future studies in this area should consider including sex hormones.

The negative link between depression and aggression in boys only appeared when $\mathrm{CAR}_{\mathrm{AUCg}}$ was $\geqslant 3.04$ S.D. above the mean. This suggests that the protective or buffering effects of high $C_{A A R_{A C g}}$ on the effect of depression on aggression in boys was not as strong as that of $\mathrm{CAR}_{\mathrm{AUCi}}$ on the effect in girls. That is, boys would only score low in aggression when CAR and depressive symptoms are low, whereas girls could also score low in violent outcomes when CAR and depressive symptoms are high. Further work to understand the mechanisms underlying these gender differences is required.

We found that the interaction effects between depression and $\mathrm{CAR}_{\mathrm{AUCg}}$ on aggression in boys differed by age. That is, when $\mathrm{CAR}_{\mathrm{AUCg}}$ was low, higher depression would lead to more aggression when the boys were older, compared with when they were younger. No age effects were found in the interaction between depression and $\mathrm{CAR}_{\mathrm{AUCi}}$ in predicting violent outcomes in girls. This might be related to gender differences in development during adolescence. On average, the onset of puberty is earlier and maturation is achieved sooner in girls than boys (Colom and Lynn, 2004). It is possible that the age effect already occurred for girls, and the age range in the current study did not capture this.
Overall, the findings suggest that prevention and intervention efforts could consider the interplay between biomarkers (such as $\mathrm{CAR}$ ) and mental health (including depressive symptoms) in predicting the risk of violence. It suggests that biological markers can provide additional information that may assist in the assessment of risk of violence and aggression, beyond current approaches that rely on historical and clinical factors.

Our study has several strengths including the longitudinal design. Repeated measures of both predictors and outcomes allowed for a within-individual design. In this study, the interaction effects referred to whether variations in CARs moderated the link between changes in depression and violent outcomes at the within-individual level. This approach enabled us to take into account time-invariant confounders such as genetic and early environmental factors (e.g. childhood adversity), which have shown consistent associations with the studied variables (Chida and Steptoe, 2009; Lewis and Plomin, 2015; Sitnick et al., 2017). In addition, compared with a single measurement of CAR, our repeated measures across three annual times increased the reliability of CAR (Hellhammer et al., 2007), especially given low stability of morning cortisol levels (Shirtcliff et al., 2005).

However, several limitations should be noted. First, the measurement of depressive symptoms and violent outcomes was based on self-report data, which might be subject to socially desirable response bias. Presence of such bias could lead to under-reporting of violence and aggression reflected by the reliability of the violent behaviours measure (which was below 0.7 in two out of three waves). However, adolescent self-report, particularly of internalizing 
problems such as depression, remains an important source of information (Sourander et al., 1999), and the measures we used demonstrate good external validity. Second, although we have tried to account for residual confounds using within-individual analyses and additionally controlled for alcohol drinking, substance use and stressful life events over time, other relevant time-varying confounding factors such as sex hormones might have been missed (Popma et al., 2007; Mehta et al., 2015; Tackett et al., 2015). More studies are needed to test for bias from unmeasured time-varying confounding. Third, we noted an average decrease in $\mathrm{CAR}_{\mathrm{AUCi}}$ for boys. Although this may be an artefact of a delay in sampling after awakening, negative $\mathrm{CAR}_{\mathrm{AUCi}}$ could occur in accurate sampling, which has been reported (Bäumler et al., 2013; Miller et al., 2013; Smyth et al., 2013). Furthermore, it has been shown that in general $\mathrm{CAR}_{\mathrm{AUCi}}$ becomes less negative with age (Platje et al., 2013). Finally, this is the first investigation, to our knowledge, of the depression-cortisol interaction effects on adolescent violent outcomes. Future research is needed to replicate these findings in different samples (e.g. clinical populations) and with different measurements of cortisol activity (e.g. hair cortisol) and reactivity (e.g. responses to social challenges) to triangulate the results.

In conclusion, this study demonstrated that CAR, including both $\mathrm{CAR}_{\mathrm{AUCg}}$ and $\mathrm{CAR}_{\mathrm{AUCi}}$, moderated the association between depressive symptoms and adolescent violent outcomes. The findings suggest that the CAR should be investigated further as a potential biological marker for violence in adolescents with high levels of depressive symptoms.

Financial support. Data from RADAR Young (Research on Adolescent Development And Relationships) were used. RADAR has been financially supported by main grants from the Netherlands Organisation for Scientific Research (NWO; GB-MAGW 480-03-005, GB-MAGW 480-08-006), and Stichting Achmea Slachtoffer en Samenleving (SASS), a grant from the NWO to the Consortium Individual Development (CID; 024.001.003), and various other grants from the NWO, the VU University Amsterdam, and Utrecht University. The first author of this study (R. Yu) is funded by a Rubicon Research Fellowship (446-15-002) from the NWO. The last author of this study (S. Fazel) is funded by the Wellcome Trust Senior Research Fellowship (202836/Z/16/Z). The funders of this research had no role in the study design, analysis and interpretation of data, writing the report, or in the decision to submit the paper for publication.

\section{Conflict of interest. None.}

Ethical standards. The authors assert that all procedures contributing to this work comply with the ethical standards of the relevant national and institutional committees on human experimentation and with the Helsinki Declaration of 1975, as revised in 2008.

\section{References}

Allison PD (2009) Fixed Effects Regression Models. London: Sage.

Arseneault L, Moffitt TE, Caspi A, Taylor PJ and Silva PA (2000) Mental disorders and violence in a total birth cohort: results from the Dunedin Study. Archives of General Psychiatry 57, 979-986.

Avenevoli S, Swendsen J, He JP, Burstein M and Merikangas KR (2015) Major depression in the national comorbidity survey-adolescent supplement: prevalence, correlates, and treatment. Journal of the American Academy of Child and Adolescent Psychiatry 54, 37-44.

Bäumler D, Kirschbaum C, Kliegel M, Alexander N and Stalder T (2013) The cortisol awakening response in toddlers and young children. Psychoneuroendocrinology 38, 2485-2492.

Bollen KA (1989) Introduction to Structural Equation Models with Latent Variables. New York: Wiley.
Byrd AL and Manuck SB (2014) MAOA, childhood maltreatment, and antisocial behavior: meta-analysis of a gene-environment interaction. Biological Psychiatry 75, 9-17.

Capaldi DM and Stoolmiller M (1999) Co-occurrence of conduct problems and depressive symptoms in early adolescent boys: III. Prediction to youngadult adjustment. Development and Psychopathology 11, 59-84.

Card NA, Stucky BD, Sawalani GM and Little TD (2008) Direct and indirect aggression during childhood and adolescence: a meta-analytic review of gender differences, intercorrelations, and relations to maladjustment. Child Development 79, 1185-1229.

Chen X, Huang X, Wang L and Chang L (2012) Aggression, peer relationships, and depression in Chinese children: a multiwave longitudinal study. Journal of Child Psychology and Psychiatry 53, 1233-1241.

Chida Y and Steptoe A (2009) Cortisol awakening response and psychosocial factors: a systematic review and meta-analysis. Biological Psychology 80, 265-278.

Clow A, Thorn L, Evans P and Hucklebridge F (2004) The awakening cortisol response: methodological issues and significance. Stress 7, 29-37.

Coid J, Yang M, Roberts A, Ullrich S, Moran P, Bebbington P, Brugha T, Jenkins R, Farrell M, Lewis G and Singleton N (2006) Violence and psychiatric morbidity in a national household population - a report from the British Household Survey. American Journal of Epidemiology 164, 1199-1208.

Colom R and Lynn R (2004) Testing the developmental theory of sex differences in intelligence on 12-18 year olds. Personality and Individual Differences 36, 75-82.

Dabbs JM, Jurkovic GJ and Frady RL (1991) Salivary testosterone and cortisol among late adolescent male offenders. Journal of Abnormal Child Psychology 19, 469-478.

Dodge KA, Coie JD and Lynam D (2006) Aggression and antisocial behavior in youth. In Handbook of Child Psychology: Social, Emotional, and Personality Development. Damon W and Lerner RM (eds). New York: Wiley, pp. 719-788.

Enzmann D, Marshall IH, Killias M, Junger-Tas J, Steketee $M$ and Gruszczynska B (2010) Self-reported youth delinquency in Europe and beyond: first results of the Second International Self-Report Delinquency Study in the context of police and victimization data. European Journal of Criminology 7, 159-183.

Fairchild G, van Goozen SH, Stollery SJ, Brown J, Gardiner J, Herbert J and Goodyer IM (2008) Cortisol diurnal rhythm and stress reactivity in male adolescents with early-onset or adolescence-onset conduct disorder. Biological Psychiatry 64, 599-606.

Fazel S, Wolf A, Chang Z, Larsson H, Goodwin GM and Lichtenstein P (2015) Depression and violence: a Swedish population study. The Lancet Psychiatry 2, 224-232.

Ferguson CJ, San Miguel C and Hartley RD (2009) A multivariate analysis of youth violence and aggression: the influence of family, peers, depression, and media violence. Journal of Pediatrics 155, 904-908.

Freitag CM, Hänig S, Palmason H, Meyer J, Wüst S and Seitz C (2009) Cortisol awakening response in healthy children and children with ADHD: impact of comorbid disorders and psychosocial risk factors. Psychoneuroendocrinology 34, 1019-1028.

Gunasekara FI, Richardson K, Carter K and Blakely T (2013) Fixed effects analysis of repeated measures data. International Journal of Epidemiology 43, 264-269.

Hawton K, Saunders KE and O'Connor RC (2012) Self-harm and suicide in adolescents. The Lancet 379, 2373-2382.

Hayes AF and Matthes J (2009) Computational procedures for probing interactions in OLS and logistic regression: SPSS and SAS implementations. Behavior Research Methods 41, 924-936.

Hellhammer DH, Wüst S and Kudielka BM (2009) Salivary cortisol as a biomarker in stress research. Psychoneuroendocrinology 34, 163-171.

Hellhammer J, Fries E, Schweisthal O, Schlotz W, Stone A and Hagemann D (2007) Several daily measurements are necessary to reliably assess the cortisol rise after awakening: state- and trait components. Psychoneuroendocrinology 32, 80-86.

Henry B, Feehan M, McGee R, Stanton W, Moffitt TE and Silva P (1993) The importance of conduct problems and depressive symptoms in predicting adolescent substance use. Journal of Abnormal Child Psychology 21, 469-480. 
Hoffmann JP and Cerbone FG (1999) Stressful life events and delinquency escalation in early adolescence. Criminology 37, 343-374.

Johnson MM, Caron KM, Mikolajewski AJ, Shirtcliff EA, Eckel LA and Taylor J (2014) Psychopathic traits, empathy, and aggression are differentially related to cortisol awakening response. Journal of Psychopathology and Behavioral Assessment 36, 380-388.

Kofler MJ, McCart MR, Zajac K, Ruggiero KJ, Saunders BE and Kilpatrick DG (2011) Depression and delinquency covariation in an accelerated longitudinal sample of adolescents. Journal of Consulting and Clinical Psychology 79, 458-469.

Lewis G and Plomin R (2015) Heritable influences on behavioural problems from early childhood to mid-adolescence: evidence for genetic stability and innovation. Psychological Medicine 45, 2171-2179.

Linder JR, Crick NR and Collins WA (2002) Relational aggression and victimization in young adults' romantic relationships: associations with perceptions of parent, peer, and romantic relationship quality. Social Development 11, 69-86.

Marsh HW, Craven RG, Parker PD, Parada RH, Guo J, Dicke T and Abduljabbar AS (2016) Temporal ordering effects of adolescent depression, relational aggression, and victimization over six waves: fully latent reciprocal effects models. Developmental Psychology 52, 1994-2009.

Mehta PH, Welker KM, Zilioli S and Carré JM (2015) Testosterone and cortisol jointly modulate risk-taking. Psychoneuroendocrinology 56, 88-99.

Miller R, Plessow F, Kirschbaum C and Stalder T (2013) Classification criteria for distinguishing cortisol responders from nonresponders to psychosocial stress: evaluation of salivary cortisol pulse detection in panel designs. Psychosomatic Medicine 75, 832-840.

Moffitt TE (1993) Adolescence-limited and life-course-persistent antisocial behavior: a developmental taxonomy. Psychological Review 100, 674-701.

Nieuwbeerta P (2002) Crime Victimization in Comparative Perspective. Den Haag, NL: Boom Juridische Uitgevers.

Pajer K, Gardner W, Rubin RT, Perel J and Neal S (2001) Decreased cortisol levels in adolescent girls with conduct disorder. Archives of General Psychiatry 58, 297-302.

Piko BF and Pinczés T (2014) Impulsivity, depression and aggression among adolescents. Personality and Individual Differences 69, 33-37.

Platje E, Jansen LM, Raine A, Branje SJ, Doreleijers TA, de Vries-Bouw M, Popma A, van Lier PA, Koot HM and Meeus WH (2013) Longitudinal associations in adolescence between cortisol and persistent aggressive or rule-breaking behavior. Biological Psychology 93, 132-137.

Popma A, Vermeiren R, Geluk CA, Rinne T, van den Brink W, Knol DL, Jansen LM, van Engeland H and Doreleijers TA (2007) Cortisol moderates the relationship between testosterone and aggression in delinquent male adolescents. Biological Psychiatry 61, 405-411.

Preacher KJ, Curran PJ and Bauer DJ (2006) Computational tools for probing interactions in multiple linear regression, multilevel modeling, and latent curve analysis. Journal of Educational and Behavioral Statistics 31, 437-448.

Pruessner JC, Kirschbaum C, Meinlschmid G and Hellhammer DH (2003) Two formulas for computation of the area under the curve represent measures of total hormone concentration versus time-dependent change. Psychoneuroendocrinology 28, 916-931.

Pruessner JC, Wolf OT, Hellhammer DH, Buske-Kirschbaum A, von Auer K, Jobst S, Kaspers F and Kirschbaum C (1997) Free cortisol levels after awakening: a reliable biological marker for the assessment of adrenocortical activity. Life Sciences 61, 2539-2549.

Quay HC (1993) The psychobiology of undersocialized aggressive conduct disorder: a theoretical perspective. Development and Psychopathology 5, 165-180.

Raine A (2002) Biosocial studies of antisocial and violent behavior in children and adults: a review. Journal of Abnormal Child Psychology 30, 311-326.

Reynolds WM (2002) Reynolds Adolescent Depression Scale: Professional Manual. Odessa, FL: Psychological Assessment Resources.

Reynolds WM (2004) Reynolds Adolescent Depression Scale: Professional Manual. In Comprehensive Handbook of Psychological Assessment, Volume 2: Personality Assessment and Psychopathology, 2nd Edn. Hersen M, Segal DL and Hilsenroth M (eds). New York: John Wiley \& Sons, pp. 224-236.

Risch N, Herrell R, Lehner T, Liang K-Y, Eaves L, Hoh J, Griem A, Kovacs M, Ott J and Merikangas KR (2009) Interaction between the serotonin transporter gene (5-HTTLPR), stressful life events, and risk of depression: a meta-analysis. JAMA 301, 2462-2471.

Roisman G, Barnett-Walker K, Owen M, Bradley R, Steinberg L, Susman E, Booth-LaForce C, Belsky J and Houts R (2009) Early family and child-care antecedents of awakening cortisol levels in adolescence. Child Development 80, 907-920.

Rowe R, Maughan B, Worthman CM, Costello EJ and Angold A (2004) Testosterone, antisocial behavior, and social dominance in boys: pubertal development and biosocial interaction. Biological Psychiatry 55, 546-552.

Rudolph KD (2009) The interpersonal context of adolescent depression. In Handbook of Depression in Adolescents. Nolen-Hoeksema S and Hilt L (eds) Hillsdale, NJ: Lawrence Erlbaum, pp. 377-418.

Scerbo AS and Kolko DJ (1994) Salivary testosterone and cortisol in disruptive children: relationship to aggressive, hyperactive, and internalizing behaviors. Journal of the American Academy of Child and Adolescent Psychiatry 33, 1174-1184.

Shirtcliff EA, Allison AL, Armstrong JM, Slattery MJ, Kalin NH and Essex MJ (2012) Longitudinal stability and developmental properties of salivary cortisol levels and circadian rhythms from childhood to adolescence. Developmental Psychobiology 54, 493-502.

Shirtcliff EA, Granger DA, Booth A and Johnson D (2005) Low salivary cortisol levels and externalizing behavior problems in youth. Development and Psychopathology 17, 167-184.

Shoal GD, Giancola PR and Kirillova GP (2003) Salivary cortisol, personality, and aggressive behavior in adolescent boys: a 5-year longitudinal study. Journal of the American Academy of Child and Adolescent Psychiatry 42, 1101-1107.

Sitnick SL, Shaw DS, Weaver CM, Shelleby EC, Choe DE, Reuben JD, Gilliam M, Winslow EB and Taraban L (2017) Early childhood predictors of severe youth violence in low-income male adolescents. Child Development 88, 27-40.

Smyth N, Clow A, Thorn L, Hucklebridge F and Evans P (2013) Delays of 5-15 min between awakening and the start of saliva sampling matter in assessment of the cortisol awakening response. Psychoneuroendocrinology 38, 1476-1483.

Sourander A, Helstelä L and Helenius H (1999) Parent-adolescent agreement on emotional and behavioral problems. Social Psychiatry and Psychiatric Epidemiology 34, 657-663.

St Clair M, Croudace T, Dunn V, Jones P, Herbert J and Goodyer I (2015) Childhood adversity subtypes and depressive symptoms in early and late adolescence. Development and Psychopathology 27, 885-899.

StataCorp (2015) Stata Statistical Software: Release 14. College Station, TX: StataCorp LP.

Statistics Netherlands (1993) Standaard Beroepenclassificatie 1992 [Standard Classification of Occupations 1992]. Voorburg, Heerlen: Netherlands Central Bureau of Statistics.

Tackett JL, Reardon KW, Herzhoff K, Page-Gould E, Harden KP and Josephs RA (2015) Estradiol and cortisol interactions in youth externalizing psychopathology. Psychoneuroendocrinology 55, 146-153.

Thapar A, Collishaw S, Pine DS and Thapar AK (2012) Depression in adolescence. The Lancet 379, 1056-1067.

van Dorn R, Volavka J and Johnson N (2012) Mental disorder and violence: Is there a relationship beyond substance use? Social Psychiatry and Psychiatric Epidemiology 47, 487-503.

Vitacco MJ, Shirtcliff E, Dismukes A and Johnson M (2015) Biomarkers, science, and the prediction of violence: clinical and legal issues. The Courts and Sciences Journal 2, 1-8.

von Polier GG, Herpertz-Dahlmann B, Konrad K, Wiesler K, Rieke J, Heinzel-Gutenbrunner M, Bachmann CJ and Vloet TD (2013) Reduced cortisol in boys with early-onset conduct disorder and callous-unemotional traits. BioMed Research International 2013, 349530.

Wüst S, Federenko I, Hellhammer DH and Kirschbaum C (2000) Genetic factors, perceived chronic stress, and the free cortisol response to awakening. Psychoneuroendocrinology 25, 707-720.

Yu R, Aaltonen M, Branje S, Ristikari T, Meeus W, Salmela-Aro K, Goodwin GM and Fazel S (2017) Depression and violence in adolescence and Young adults: Findings from three longitudinal cohorts. Journal of the American Academy of Child and Adolescent Psychiatry 56, 652-658. 